\title{
The Extensionality of Parthood and Composition
}

\author{
Achille C. Varzi \\ Department of Philosophy, Columbia University, New York
}

[Final version published in The Philosophical Quarterly 58 (2008), 108-133]

\begin{abstract}
I focus on three mereological principles: the Extensionality of Parthood (EP), the Uniqueness of Composition (UC), and the Extensionality of Composition (EC). These principles are not equivalent. Nonetheless, they are closely related (and often equated) as they all reflect the basic nominalistic dictum, no difference without a difference maker. And each one of them-individually or collectively - has been challenged on philosophical grounds. In the first part I argue that such challenges do not quite threaten EP insofar as they are either self-defeating or unsupported. In the second part I argue that they hardly undermine the tenability of UC and EC as well.
\end{abstract}

\section{No Difference without a Difference Maker}

Classical mereology - the theory of parts and wholes - is extensional; it says that no two objects can be mereologically indiscernible. In standard treatments, this is expressed by the following Extensionality of Parthood principle-sometimes assumed as an axiom, more often derived as a theorem:

EP If $x$ and $y$ are composite objects with the same proper parts, then $x=y$.

By a composite object I mean anything that has proper parts, i.e., parts distinct from the whole. It is, of course, crucial that EP be restricted to such objects, otherwise the principle would be trivially false: any two mereological simples, or atoms, are bound to have the same proper parts vacuously. On the other hand, it is also crucial that EP be phrased in terms of proper parts, otherwise the principle would be trivially true: to the extent that parthood is reflexive and antisymmetric, as we may assume, having all parts in common-proper or improper-implies being part of each other (by reflexivity), hence being identical (by antisymmetry). ${ }^{1}$ Thus, EP is by no means a platitude, just as it is not an absurdity. It is a genuine identity criterion for those objects that exhibit some mereological complexity. Not only is sameness of proper parts necessary for identity (a trivial consequence of the indiscernibility of identicals); it is also sufficient.

${ }^{1}$ This is sometimes overlooked in the literature; see e.g. M. Johnston, 'Constitution Is Not Identity', Mind, 101 (1992), pp. 89-105, at p. 93. 
This principle is closely related to, and often identified with, what has come to be known as the Uniqueness of Composition thesis: ${ }^{2}$

UC If $x$ and $y$ are sums of the same things, then $x=y$,

where

(1) $\quad x$ is a sum of the $z \mathrm{~s}=_{\mathrm{df}}$ The $z \mathrm{~s}$ are all parts of $x$ and every part of $x$ has a part in common with at least one the $z$ s.

Since 'sum' is a term of art, the extensional import of this principle is perhaps less transparent, but it is easy to see where it lies. Suppose we have a house made of Tinkertoy pieces. Then the house qualifies as a sum of those pieces: each piece is part of the house and each part of the house overlaps at least one of the pieces (assuming that the house is just the solid object and not, say, the object together with its empty interior.) Are there other things that qualify as sums of those pieces? UC says there aren't; the house is the only candidate: it is the sum of those pieces. For another example, consider the following three things: the top third of the house, the middle half of the house, and the bottom third. Then, again, the house as a whole qualifies as a sum of those three things, since each of them is part of the house and each part of the house overlaps at least one of them. So, again, UC says that the house is the only such sum. And so on.

There is also a third mereological principle that is worth mentioning in this connection. It does not come with a standard tag and in the literature it is often identified with either EP or UC (or both), but to give it a name I shall label it the Extensionality of Composition: ${ }^{3}$

EC If $x$ and $y$ are composed of the same things, then $x=y$, where

(2) $\quad x$ is a composed of the $z \mathrm{~s}=_{\mathrm{df}} x$ is a sum of the $z \mathrm{~s}$ and the $z \mathrm{~s}$ are pairwise disjoint (i.e., no two of them have any parts in common).

In our example, the house is in fact composed of the individual Tinkertoy pieces, since no two pieces have parts in common. The house is not, however, composed

${ }^{2}$ See P. van Inwagen, Material Beings (Ithaca, NY: Cornell University Press, 1990), at p. 39, and D. K. Lewis, Parts of Classes (Oxford: Blackwell, 1991), at p. 74. The identification of EP with UC is explicit, for instance, in G. Rosen and C. Dorr, 'Composition as a Fiction', in R. Gale (ed.), The Blackwell Guide to Metaphysics (Oxford: Blackwell, 2002), pp. 151-174, at p. 154.

${ }^{3}$ For instance, it is with reference to EC (where the zs are atoms) that N. Goodman illustrates the extensional character of the calculus of individuals; see his 'A World of Individuals', in J. M. Bochenski, A. Church, and N. Goodman, The Problem of Universals. A Symposium (Notre Dame: University of Notre Dame Press, 1956), pp. 13-31, sect. 2. 
of its top third, its middle half, and its bottom third, since these three parts are not pairwise disjoint. Still, any sum of such parts also qualifies as a sum of the individual Tinkertoy pieces that compose them, and is in fact composed of those Tinkertoy pieces. So EC says that the house and any such sum are, in the end, one and the same whole: the house is the only thing composed of those Tinkertoy pieces.

Now, these three principles are, as I said, closely related and often identified, and in a way they all express the same nominalist intuition: No difference without a difference maker. They are, however, distinct. Obviously UC implies EC. And it implies EP as well, since every composite object qualifies as a sum of all of its proper parts. Every other implication, however, fails. On the one hand, it is easy to see that EP implies neither UC nor EC. As a counterexample, consider a model such as is depicted in Figure 1, with parthood going uphill along the lines. There are four composite objects in this model $\left(a_{1}, a_{2}, b_{1}\right.$, and $\left.b_{2}\right)$ and all have distinct proper parts, so EP holds. Yet both $a_{1}$ and $a_{2}$ are sums of $c_{1}, c_{2}$, and $c_{3}$, so UC fails; and since $c_{1}, c_{2}$, and $c_{3}$ are atomic, hence pairwise disjoint, EC fails as well. On the other hand, it is also easy to see that EC implies neither EP nor UC. As a counterexample, consider an infinite, non-atomistic model such as is depicted in Figure 2. In this model, all non-atoms overlap one another, so EC holds vacuously (there are no things of which $a_{1}$ and $a_{2}$ are composed). Yet EP fails, since $a_{1}$ and $a_{2}$ are distinct in spite of sharing the same proper parts; and since both $a_{1}$ and $a_{2}$ qualify as sums of $b_{1}$ and $b_{2}$, UC fails as well.

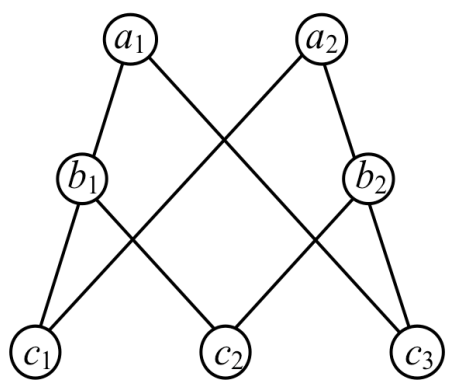

Figure 1

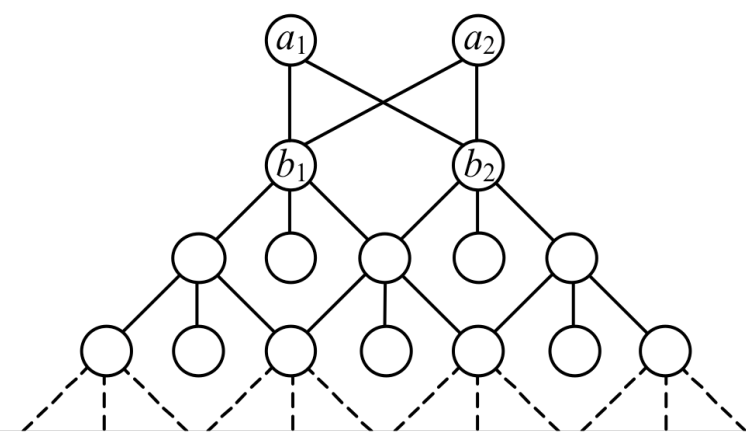

Figure 2

Of course, these are abstract models, and whether there are any objects that fit the bill is precisely the sort of question a philosopher may want to ask. But let us put that question aside for a moment. Surely both models satisfy the following Proper Composition principle, also known as Weak Supplementation: ${ }^{4}$

${ }^{4}$ Cf. P. M. Simons, Parts. A Study in Ontology (Oxford: Clarendon, 1987). 
WS If $x$ is a proper part of $y$, then $y$ has a part $z$ disjoint from $x$.

This principle expresses a minimal requirement that any relation must satisfy (besides reflexivity, antisymmetry, and transitivity) if it is to qualify as parthood at all, so the models are not idle. ${ }^{5}$ As far as the meaning of 'part' is concerned, the situations depicted in Figure 1 and Figure 2 show that there is no obvious reason to equate those three principles. They are similar enough, but on the face of it the similarity falls short of equivalence.

\section{The Deadlock}

So, now, is any of those principles philosophically disputable? For a classical mereologist they are all true, of course, indeed necessarily true. And I agree: No difference without a difference maker. Not everybody, however, shares the extensional intuition-and the objection is familiar enough. ${ }^{6}$ For a popular example, consider again a house built out of wooden Tinkertoy pieces and suppose that this house is now on an otherwise empty shelf. Let

(3) $\alpha==_{\mathrm{df}}$ the house that is now on the shelf

(4) $\quad \beta==_{\mathrm{df}}$ the wood that is now located where $\alpha$ is located

(and assume that both definitions successfully pick out an existing object ${ }^{7}$ ). Then the objection is that the identity

${ }^{5}$ To be sure, there are theories that violate WS. For Brentano, for instance, a soul is a proper part of a thinking soul even though there is nothing to make up for the difference (see his Kategorienlehre, ed. by A. Kastil, Hamburg: Meiner, 1933; Eng. trans. by R. M. Chisholm and N. Guterman: The Theory of Categories, The Hague: Nijhoff, 1981). Similarly, in K. Fine's theory of qua objects, Socrates counts as a proper part of Socrates qua human (see 'Acts, Events, and Things', in W. Leinfellner, E. Kraemer, and J. Schank, eds, Language and Ontology. Proceedings of the 6th International Wittgenstein Symposium, Vienna: Hölder-Pichler-Tempsky, 1982, pp. 97-105). Here I follow Simons, Parts, in regarding such theories as not properly mereological. Ditto for those theories where parthood is not a partial order, for instance because it violates transitivity (as urged since N. Rescher, 'Axioms for the Part Relation', Philosophical Studies 6 (1955), pp. 8-11).

${ }^{6}$ This line of objection has become popular with D. Wiggins, 'On Being in the Same Place at the Same Time', Philosophical Review, 77 (1968), pp. 90-95. As it stands, the example below follows J. J. Thomson, 'Parthood and Identity Across Time', Journal of Philosophy, 80 (1983), pp. 201-220.

${ }^{7}$ Some might question that artifacts such as $\alpha$ exist at all; see e.g. P. van Inwagen, 'When Are Objects Parts?', Philosophical Perspectives, 1 (1987), pp. 21-47. Such philosophers might want to reinterpret the example by taking $\alpha$ to be a suitable sort of entity (e.g., the cat that is now on the mat) and $\beta$ the underlying matter (e.g., the feline tissue on the mat). Also, some might want to draw a distinction between the wood that is on the shelf and the portion of wood that is on the shelf (or, better, the mass of wood on the shelf), treating only the latter as an individual object; see e.g. H. Laycock, 'Some Questions of Ontology', Philosophical Review, 81 (1972), pp. 3-42. I don't follow 
fails to obtain insofar as $\alpha$ enjoys properties that are lacked by $\beta$, or vice versa. For instance, it is argued that

(a) $\alpha$, but not $\beta$, would survive the annihilation of a single Tinkertoy piece.

Or it is argued that

(b) Taking the Tinkertoy pieces apart would destroy $\alpha$ but not $\beta$.

Or, again, that

(c) $\alpha$ is necessarily house-shaped, whereas $\beta$ isn't.

Accordingly, $\alpha$ and $\beta$ would have different properties and should therefore be distinguished by Leibniz's Law (the "indiscernibility of identicals"). ${ }^{8}$ And since $\alpha$ and $\beta$ appear to be mereologically indiscernible, i.e., to have exactly the same proper parts, this outcome would contradict EP, as well as UC and EC. (If $\alpha$ and $\beta$ have the same proper parts, then they surely qualify as sums of the same Tinkertoy pieces - in fact, as objects composed of those pieces.)

There are two main responses that mereological extensionalists have pursued in an effort to resist this line of objection. The first one involves an appeal to Humean supervenience and the so-called "grounding problem". How can $\alpha$ and $\beta$ differ in their modal properties if their actual properties coincide (same location but also same shape, same weight, same color, etc.)? In virtue of what would their modal properties diverge? ${ }^{9}$ I myself find this line of defense compelling enough. Others, however, are left unmoved, as they find the notion of Humean supervenience just as controversial as the extensionality thesis that it is supposed to

the distinction here, but those who do should understand ' $\beta$ ' as a singular term for this individual object (rather than a plural term for its constituents). Finally, I am assuming for simplicity that the spatial location of $\alpha$ is given by the location of the Tinkertoy pieces; it does not, for instance, encompass the location of the interior of the house, if this is empty. This assumption may be questioned (see e.g. K. Fine, 'The Non-Identity of a Material Thing and Its Matter', Mind, 112 (2003), pp. 195-234, at p. 198), but nothing significant hinges on it.

${ }^{8}$ There are variants of the objection that appeal to temporal properties instead, beginning with Thomson's original formulation. I shall not consider such variants, as I think the difference between alethic and temporal modalities is ultimately irrelevant to what follows.

${ }^{9}$ See e.g. M. Burke, 'Copper Statues and Pieces of Copper: A Challenge to the Standard Account', Analysis, 52 (1992), pp. 12-17; D. W. Zimmerman, 'Theories of Masses and Problems of Constitution', Philosophical Review, 104 (1995), pp. 53-110; S. Levey, 'Coincidence and Principles of Composition', Analysis, 57 (1997), pp. 1-10; T. Sider, 'Global Supervenience and Identity Across Times and Worlds', Philosophy and Phenomenological Research, 59 (1999), pp. 913-937; and E. Olson, 'Material Coincidence and the Indiscernibility Problem', Philosophical Quarterly, 51 (2001), pp. 337-355. 
help. ${ }^{10}$ Besides, although the objection thus formulated relies explicitly on the appeal to modal properties, one might as well bring up properties whose modal status is at least contentious-e.g., artistic properties: ${ }^{11}$

(d) $\quad \alpha$ is in Victorian style, whereas $\beta$ isn't.

So this line of response on behalf of the extensional credo can hardly hope to go through unchallenged.

The second line of response is metaphysically less controversial. In fact, it does not depend on any metaphysical views at all but, rather, on linguistic considerations. According to this line of response, the intuitive truth of such claims as (a)-(d) is not to be taken to reflect a difference in the properties enjoyed by $\alpha$ and $\beta$, but just a difference in the predicates by means of which we can identify what is now on the shelf. ${ }^{12}$ We may conceive of the object on the shelf as a house or as a mass of wood - the response continues - and depending on how we conceive of it we may be inclined to say certain things rather than others. However, this is not enough to conclude that we are speaking of different things unless we are speaking transparently. Surely we would not wish to deny the truth of

(6) the number of planets $=9$

simply because we have good reasons to make such statements as

(7) It is possible that the number of planets is even, impossible that 9 is even.

This is because the context 'It is possible that...' is not transparent: it does not license the application of Leibniz's law. To put it differently, (7) is true on a de dicto reading, where the modal operator has wide scope, but of course it is only a de re reading of (7) that would warrant the denial of (6) by Leibniz's law. And on

${ }^{10}$ See e.g. M. C. Rea, 'Supervenience and Co-Location', American Philosophical Quarterly, 34 (1997), pp. 367-375; E. J. Lowe, 'Form Without Matter', Ratio, 11 (1998), pp. 214-234, at p. 223; K. Bennett, 'Spatio-Temporal Coincidence and the Grounding Problem', Philosophical Studies, 118 (2004), pp. 339-371; K. Koslicki, 'Constitution and Similarity', Philosophical Studies, 117 (2004), pp. 327-364.

${ }^{11}$ See e.g. J. Levinson, 'A Note on Categorical Properties and Contingent Identity', Journal of Philosophy, 85 (1988), pp. 718-722. For a larger choice of examples, see K. Fine, 'The NonIdentity of a Material Thing and Its Matter', at pp. 206-207.

${ }^{12}$ For this line of response, see e.g. D. K. Lewis, 'Counterpart of Persons and Their Bodies', Journal of Philosophy, 68 (1971), pp. 203-211; D. Robinson, 'Can Amoebae Divide Without Multiplying?', Australasian Journal of Philosophy, 63 (1985), pp. 299-319; H. Noonan, 'Indeterminate Identity, Contingent Identity, and Abelardian Predicates', Philosophical Quarterly, 41 (1991), pp. 183-193; M. Jubien, Ontology, Modality, and the Fallacy of Reference (Cambridge: Cambridge University Press, 1993); and (from a slightly different perspective) M. Della Rocca, 'Essentialists and Essentialism', Journal of Philosophy, 93 (1996), pp. 186-202. 
a de re reading, (7) is false. So why should (a)-(d) be handled differently? Why should we be inclined to think that the contexts employed in such statements are transparent? What evidence can the anti-extensionalist produce to back up a de re reading of those statements without begging the question?

This second line of response is, I think, more effective. ${ }^{13}$ It does not amount to a direct defense of any of EP, UC, or EC, but it gives voice to a legitimate form of skepticism concerning the viability of the opponent's strategy. We can hardly ground the truth of de re claims on linguistic practices and intuitions. On the other hand, it is up to the extensionalist to argue that every linguistic context employed in the putative counterexamples - not only (a)-(c) but also (d) and the like-is opaque in the relevant sense. And it is up to the extensionalist to show that the linguistic implications and complications deriving from the claim that every such context is opaque are not intolerable. ${ }^{14}$

So, as things stand, I think there is some truth to the thought that disputes on these matters are at a deadlock. There is no obvious reason to take mereological extensionality for granted (except perhaps considerations of ontological simplicity and nominalistic parsimony), but neither is there a knockdown argument against it, and it appears as though we have an ontological question that can only be settled by looking at its tenability vis-à-vis our linguistic intuitions.

Perhaps this is a sign of the spurious nature of the issue. Perhaps there simply is no way of assessing the extensionalist perspective on neutral grounds. One would need to be clear about the metaphysical make-up of the entities that fall into the scope of mereology - the nature of such things as $\alpha$ and $\beta$, for instancebefore spelling out the details. And surely enough there are ways of doing this that, if accepted, would allow one to stick to a fool-blooded extensionalist mereology while at the same time accepting the de re truth of any putative counterexamples. For instance, if $\alpha$ and $\beta$ were construed as four- or perhaps five-dimensional entities spanning across times or across worlds, then the problem would dissolve insofar as the extensionalist could just agree on (a)-(d) and, consequently, on the falsity of (5). $\alpha$ and $\beta$ would not have the same spatio-temporal parts ( $\alpha$ 's life being shorter), or at least not the same spatio-temporal-modal parts ( $\beta$ 's life extending only to those worlds that include all the Tinkertoy pieces), so EP would not be affected by the falsity of (5). And for the very same reasons, UC and EC would not be affected either. ${ }^{15}$ It is in fact widely acknowledged that mereological extension-

\footnotetext{
${ }^{13}$ I myself follow it in my 'Mereological Commitments', Dialectica, 54 (2000), pp. 283-305.

${ }^{14} \mathrm{~K}$. Fine, for example, has argued that they are; see his 'The Non-Identity of a Material Thing and Its Matter'.

15 The four-dimensionalist way out is offered e.g. by D. K. Lewis, On the Plurality of Worlds (Oxford: Blackwell, 1986), M. Heller, The Ontology of Physical Objects: Four Dimensional Hunks
} 
alism sits well with a four- or five-dimensional metaphysics (as it is a fact that anti-extensionalist philosophers are usually attracted by different metaphysics, on which both $\alpha$ and $\beta$ are construed as enduring, three-dimensional, world-bound entities). So, provided one accepts certain metaphysical views, one might easily settle the issue in favor of an extensional mereology, just as one may settle the issue against it on the grounds of a different metaphysical picture. Look at the whole package and make up your mind, as the saying goes.

If this were right, then it would follow that mereology is not truly a piece of formal ontology, contrary to standard lore. Formal ontology is supposed to be metaphysically neutral; it is supposed to be formal precisely insofar as it aims to be a general, domain-independent theory - a theory of certain formal structures that are realized or exemplified by whatever there is, no matter what it is. ${ }^{16}$ If the basic principles governing part-whole structures could only be justified by appealing to one's overall metaphysical views, then they would not pass muster and mereology would become part and parcel of those views.

I do not think we should draw this conclusion, though. It is precisely here that the non-equivalence between EP and its two variants, UC and EC, comes into the picture. In what follows I will argue that the anti-extensionalist objection, if accepted, only affects the status of UC and EC. It does not, on certain plausible assumptions, refute the tenet that parthood is an extensional relation; at best it casts doubts on the cognate tenets that composition is unique and extensional. And denial of such tenets is no straightforward mereological heresy (heretical as it might be for a nominalist mereologist). At the same time, however, I will also suggest that once the anti-extensionalist objection to EP is rejected, we have good reasons to reject it also on behalf of UC and EC. For the defense of EP will rely on the claim that the objection carries unwarranted presuppositions. And unless such presuppositions can be justified (which I will dispute) UC holds true as well, hence so does EC.

of Matter (Cambridge: Cambridge University Press, 1990), and T. Sider, Four-Dimensionalism: An Ontology of Persistence and Time (New York: Oxford University Press, 2001). The fivedimensionalist way out is outlined in G. Schlesinger, 'Spatial, Temporal, and Cosmic Parts', Southern Journal of Philosophy, 23 (1985), pp. 255-271, and in my 'Parts, Counterparts, and Modal Occurrents', Travaux de Logique, 14 (2001), pp. 151-171.

${ }^{16}$ This conception of formal ontology as metaphysically neutral is rooted in Husserl's Logical Investigations (Halle: Niemeyer, 2nd ed. 1913; Eng. trans. by J. N. Findlay, London: Routledge \& Kegan Paul, 1970). Whether mereology is "neutral" in this sense is not, of course, the same question as whether it is "innocent" in the sense of Lewis (Parts of Classes, at p. 82). Nor it is the same as the question of whether parthood is the only fundamental mode of composition, so I don't think that the conception as such implies what C. McDaniel calls compositional "monism" ("Modal Realism with Overlap', Australasian Journal of Philosophy, 82 (2004), pp. 137-152). 


\section{The Extensionality of Parthood - I}

Here is why I think that EP is, contrary to appearances, not affected by the sort of objection illustrated above. Consider again the identity in (5), or rather its negation:

$$
\alpha \neq \beta .
$$

Suppose, for the sake of the argument, that we agree on (8). In order for this to count as a counterexample to EP, $\alpha$ and $\beta$ would have to be mereologically indiscernible. That is, the following would have to hold, too:

$$
\alpha \text { and } \beta \text { have the same proper parts. }
$$

This, however, need not be true. There are two ways of proving this claim, depending on whether or not one thinks that the wood is part of the house, i.e., depending on whether or not the following is accepted:

(10) $\beta$ is part of $\alpha$.

Case 1 is straightforward. Suppose we accepted (10), as Aristotle and many others since have suggested. ${ }^{17}$ Then $\beta$ would have to be a proper part of $\alpha$, because of (8). But surely $\beta$ is not a proper part of itself - nothing is. So $\alpha$ and $\beta$ would not be mereologically indiscernible after all: the former would, while the latter would not, include $\beta$ among its proper parts. Hence (9) would be false. And if (9) is false, EP is vacuously safe. (Note that this argument does not presuppose the antisymmetry of parthood. As I mentioned, I take it that antisymmetry is one of the minimal requirements that any relation must satisfy in order to qualify as parthood, but some may feel otherwise. ${ }^{18}$ In particular, the anti-extensionalist who is willing to accept (10) might also be inclined to accept its converse, i.e.

${ }^{17}$ See Aristotle, Metaphysics, $\Delta, 1023 \mathrm{~b}$. Recent endorsers of the view that the stuff an object is made of is part of the object include, for instance, S. Haslanger, 'Parts, Compounds, and Substantial Unity', in D. Charles, M. L. Gill, and T. Scaltsas (eds), Unity and Identity of Aristotelian Substances (Oxford: Oxford University Press, 1994), pp. 129-170, and J. J. Thomson, 'The Statue and the Clay', Noûs, 32 (1998), pp. 149-173. Most constitution-theorists, however, disagree: see e.g. E. J. Lowe, 'Form Without Matter', at p. 220, and L. R. Baker, 'Unity without Identity: A New Look at Material Constitution', Midwest Studies in Philosophy, 23 (1999), pp. 144-165, at p. 146.

${ }^{18}$ For instance, independently of the issues discussed here, D. Sanford offers Borges's Aleph as a counterexample to antisymmetry: "I saw the earth in the Aleph and in the earth the Aleph once more and the earth in the Aleph ..."; see 'The Problem of the Many, Many Composition Questions, and Naive Mereology', Noûs, 27 (1993), 219-228, at p. 222. This may be pure fantasy; nonetheless, the possibility of mereological loops may be worth considering if one is interested in mereological analogues of non-well-founded set theory, following P. Aczel, Non-Well-Founded Sets (Stanford: CSLI Publications, 1988). This is particularly significant insofar as set theory itself may be reformulated in mereological terms, as in Lewis's Parts of Classes. 
while insisting on (8). ${ }^{19}$ Pretty clearly, this is not enough to block the argument, which could now be run twice.)

Case 2-where (10) is rejected-is less obvious. Suppose (10) is false. I submit that whatever reasons would warrant the non-identity in (8) would also warrant a host of non-identity statements concerning $\alpha$ 's and $\beta$ 's proper parts. Consider, for instance, the following items:

(3) $\quad \alpha_{1}=$ ef $_{\text {df }}$ the roof of the house that is now on the shelf

(4) $\quad \beta_{1}=\mathrm{df}_{\mathrm{df}}$ the wood that is now located where $\alpha_{1}$ is located

(and assume that each definition successfully picks out an existing object ${ }^{20}$ ). Insofar as $\alpha$ and $\beta$ should be distinguished in view of (a)-(d), it is reasonable to suppose that similar differences should also hold between $\alpha_{1}$ and $\beta_{1}$-for instance:

$\left(a_{1}\right) \quad \alpha_{1}$, but not $\beta_{1}$, would survive the annihilation of a single Tinkertoy piece.

$\left(b_{1}\right) \quad$ Taking the Tinkertoy pieces apart would destroy $\alpha_{1}$ but not $\beta_{1}$.

(c) $\alpha_{1}$ is necessarily roof-shaped, whereas $\beta_{1}$ isn't.

(d $d_{1} \quad \alpha_{1}$ is well designed, whereas $\beta_{1}$ isn't.

Accordingly, if (8) is accepted, then it is reasonable to suppose that $\left(8_{1}\right)$ should be accepted as well:

$\left(8_{1}\right) \quad \alpha_{1} \neq \beta_{1}$.

But then, again, we should conclude that $\alpha$ and $\beta$ do not have the same proper parts. For on the one hand, the falsehood of (10) should be mirrored in the falsehood of

(10) $\quad \beta_{1}$ is part of $\alpha_{1}$.

And if $\beta_{1}$ is not part of $\alpha_{1}$, I don't see any reason to think that it should be part of $\alpha$. On the other hand-and independently of this - although it is obvious that $\alpha_{1}$ is part of $\alpha$, there is no reason to think that $\alpha_{1}$ is also part of $\beta .{ }^{21}$ On the contrary: re-

${ }^{19}$ This is J. J. Thomson's position, for instance (in both papers cited).

${ }^{20}$ This assumption is not strictly necessary. Some philosophers might have independent reasons for denying that such "arbitrary undetached parts" as $\alpha_{1}$ and $\beta_{1}$ exist; see P. van Inwagen, 'The Doctrine of Arbitrary Undetached Parts', Pacific Philosophical Quarterly, 62 (1981), pp. 123-137. In that case we could still spell out the argument with respect to other parts (e.g., the Tinkertoys) or else treat either $\alpha$ or $\beta$ as atomic. Both options are covered by the discussion that follows.

${ }^{21}$ This point is explicitly acknowledged by some anti-extensionalists; see e.g. K. Fine, 'The Non-Identity of a Material Thing and Its Matter', at p. 198. 
gardless of whether we construe $\beta$ as a homeomerous or heteromerous stuff, insofar as it is supposed to be a mere mass of wood, every (reasonably large) part of $\beta$ must be a mass of wood, too-and we are supposing that this is true of $\beta_{1}$, not of $\alpha_{1} . \alpha_{1}$ is not a mere mass of wood. Either way, we must therefore conclude that $\alpha$ and $\beta$ do not in fact share the same proper parts, contrary to (9). And if (9) is false, then again the truth of (8) does not constitute a counterexample to EP.

This is, admittedly, only the beginning of an argument for Case 2. For the reasoning above only disposes of (8), yet the objection to EP may crop up at lower levels of analysis. Indeed, doesn't it already resurface in view of $\left(8_{1}\right)$ ? Have we not found two other objects, $\alpha_{1}$ and $\beta_{1}$, that violate EP? The answer is that the objection does indeed resurface at this level-but so does the response. The non-identity $\left(8_{1}\right)$ is a threat to EP only if the following holds, too:

(9) $\quad \alpha_{1}$ and $\beta_{1}$ have the same proper parts.

But look closely and you'll see that the anti-extensionalist should regard $\left(9_{1}\right)$ as false, too (for example because she should think that $\alpha_{1}$ does, while $\beta_{1}$ does not, include the right half of the roof as a proper part). We may in fact suppose that this pattern of reasoning is reiterated until we reach a bottom level, where a single Tinkertoy piece is at issue. Let

$\left(3_{n}\right) \quad \alpha_{n}=_{\mathrm{df}}$ a certain Tinkertoy piece

$\left(4_{n}\right) \quad \beta_{n}=$ df the wood that is now located where $\alpha_{n}$ is located.

Then the response will at this point contend that the sort of intuition offered in support of $(8),\left(8_{1}\right)$, and so on should also warrant

$$
\left(8_{n}\right) \quad \alpha_{n} \neq \beta_{n} .
$$

And this contention is enough to block the objection to EP at every intermediate level. Of course, the contention founders if one keeps thinking in terms of annihilation or disassembly of Tinkertoy pieces, as in (a)-(b) and $\left(a_{1}\right)-\left(b_{1}\right)$. For, obviously, $\alpha_{n}$ cannot survive the annihilation of any Tinkertoy piece (it $i$ s a Tinkertoy piece), and equally obviously it can survive if the Tinkertoy pieces are taken apart. In these respects, $\alpha_{n}$ and $\beta_{n}$ are not dissimilar. Neither can the contention be safely cashed out by speaking of annihilation or disassembly of smaller parts-for instance, molecules - for intuitions about the survival conditions of a mass of wood may vary as we go down to its chemical composition. Still, we could now say that if (c)-(d) and $\left(c_{1}\right)-\left(d_{1}\right)$ are found compelling, for example, then claims such as the following should be found compelling, too:

(c $\left.c_{n}\right) \quad \alpha_{n}$ is necessarily Tinkertoy-shaped, whereas $\beta_{n}$ isn't.

(d $\mathrm{d}_{n} \quad \alpha_{n}$ is badly made (say), whereas $\beta_{n}$ isn't. 
We may at this point distinguish two sub-cases: either at least one of $\alpha_{n}$ and $\beta_{n}$ is mereologically atomic, or neither is. In the first case, the non-identity in $\left(8_{n}\right)$ has no bearing on the truth of EP, since EP says nothing at all about the identity or distinctness conditions of atomic objects (as it says nothing at all about whether or not distinct objects may be co-located; if EP ruled that out, then we would be wasting our time, as we are working precisely on the hypothesis that $\alpha$ and $\beta$ are colocated). In the second case, where both $\alpha_{n}$ and $\beta_{n}$ are composite, we may just continue by the same pattern: consider the right half of $\alpha_{n}$ and the underlying woodet cetera. Why should the rationale underlying (c)-(d) apply only above a certain level of decomposition? The burden of blocking this regress is entirely on the objector. No matter how deep we dig, if one has reasons to distinguish between $\alpha$ and $\beta$ one may always find reasons to distinguish also between $\alpha$ 's proper parts (and proper parts thereof) and $\beta$ 's-or so I submit. So if one's misgivings about EP stem from one's intuitions concerning properties that differentiate an object from its co-located stuff, then one ought to find the distinction of any part of $\alpha$ and the underlying stuff plausible as well. And this suffices to undermine those very misgivings.

\section{The Extensionality of Parthood - II}

If this is correct, then we should conclude that the standard line of objection to EP is simply self-defeating. At least with respect to material objects, the objection trades on the supposition that co-location of non-identicals is possible at some level of mereological composition but not at other, lower levels - and this supposition cries for a justification. ${ }^{22}$

I will come back to this supposition in a moment. First, let me note that this line of defense on behalf of EP is still defective in one important respect. It disposes of the counterexample insofar as the putatively distinct entities are a certain material object, $\alpha$, and the corresponding amount of matter, $\beta$. Not much depends on the fact that $\alpha$ is an artifact; we could take $\alpha$ to be a cat and run the argument just as smoothly. However, a lot depends on the fact that $\beta$ is construed as a "mere" mass of stuff, as opposed, for example, to a "mere" aggregate of pieces. Often, the anti-extensionalist objection is stated precisely with reference to such aggregates, the idea being that their identity and individuation conditions are determined exclusively by the identity and individuation conditions of the pieces

\footnotetext{
${ }^{22}$ In the case of abstract entities (assuming that they are mereologically structured) co-location plays no role and the objection should be taken at face value. See the 'Fallout'/'Outfall' example of Section 6. Typically, however, it is the mereological extensionality of spatio-temporal particulars that has been questioned, so it seems fair to phrase the challenge in terms of co-location.
} 
they consist of. ${ }^{23}$ If we take $\beta$ to be an aggregate thus conceived, then the objection still applies - as long as (a)-(d) are granted-but the response outlined above doesn't go through as smoothly. More precisely, it is Case 2 of the argumentwhere $\beta$ is not construed as part of $\alpha$ (nor $\alpha$ as part of $\beta$ ) - that doesn't go through smoothly. It is still reasonable to respond that certain parts of $\alpha$, such as the roof, are not part of $\beta$ insofar as they are not "mere" aggregates of Tinkertoy pieces. (If $\alpha_{1}$-the roof-were part of $\beta$, and if it can survive the annihilation of a Tinkertoy piece, then why shouldn't the whole of $\beta$ survive too? Alternatively, if $\beta_{1}$-the mere aggregate of the Tinkertoys that make up the roof-were part of $\alpha$, then why shouldn't the whole of $\beta$ be part of $\alpha$ ?) This would dispose of the putative nonidentity of $\alpha$ and $\beta$ without rejecting EP. But it would appear that this tu quoque line of reasoning could not be reiterated at every level of mereological decomposition. Eventually we are bound to reach a point where we are forced to distinguish a proper part of $\alpha$, say $\alpha_{j}$, and a corresponding proper part of $\beta$, say $\beta_{j}$, whose proper parts do not include any sums of Tinkertoy pieces. For example, let

(3) $\quad \alpha_{j}=$ a little window sill composed of just two Tinkertoy pieces, $\mathrm{T}_{1}$ and $\mathrm{T}_{2}$.

(4) $\quad \beta_{j}=$ the mere aggregate of $\mathrm{T}_{1}$ and $\mathrm{T}_{2}$.

The truth of

$\left(9_{j}\right) \quad \alpha_{j}$ and $\beta_{j}$ have the same proper parts

would seem to be non-negotiable. Hence accepting the non-identity

$\left(8_{j}\right) \quad \alpha_{j} \neq \beta_{j}$

(for instance on account of the fact that taking $\mathrm{T}_{1}$ and $\mathrm{T}_{2}$ apart would destroy $\alpha_{j}$ but not $\beta_{j}$ ) would amount to a definite rejection of EP. What could the extensionalist say at that point?

Well, the extensionalist is going to challenge $\left(9_{j}\right)$. The objector is pushing for a distinction between two sorts of composite object, each with its own identity conditions: "integral wholes", whose identity and survival conditions are not determined exclusively by the identity and individuation conditions of their parts, and "mere aggregates". From $\alpha$ all the way down to $\alpha_{j}$ we have instances of the first sort of composite; from $\beta$ all the way down to $\beta_{j}$ we have instances of the second sort. But consider now the two parts of our Tinkertoy pieces that are adjacent to each other-say the right half of $T_{1}, R_{1}$, and the left half of $T_{2}, L_{2}$ (Figure 3). Surely the anti-extensionalist should distinguish here between the "integral" com-

\footnotetext{
${ }^{23}$ For a representative formulation, see E. J. Lowe, Kinds of Being. A Study of Individuation, Identity and the Logic of Sortal Terms (Oxford: Blackwell, 1989), ch. 6.
} 
posite of such parts - the middle of the windowsill, as we may call it - and the "mere" aggregate of those parts. After all, taking $\mathrm{T}_{1}$ and $\mathrm{T}_{2}$ apart would destroy the former, not the latter. And this would be enough to trigger the usual pattern of reasoning and force the conclusion that $\alpha_{j}$ and $\beta_{j}$ do not, in fact, have the same proper parts, contrary to $\left(9_{j}\right)$.

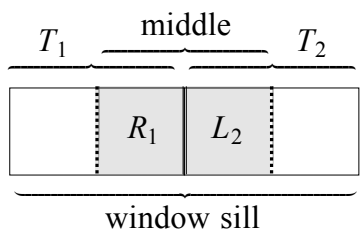

Figure 3

It is only when we reach a bottom level that rules out any further decomposition that this tu quoque line of reasoning cannot be applied on behalf of $\mathrm{EP}$ - only when we reach a point where we are supposed to distinguish a proper part of $\alpha$ and a corresponding proper part of $\beta$ all of whose proper parts are mereological atoms. At that point, indeed, the putative difference between such mereologically indiscernible entities would provide a counterexample to EP. But then the extensionalist can say two things.

On the one hand, this means that the only possible counterexamples to EP involve atomistic worlds: a world consisting of mereologically atomless gunk appears to be perfectly extensional. In other words, if there are no atoms, then the situation is similar to the situation examined in the previous section; no matter how deep we dig, if we have reasons to distinguish between $\alpha$ and $\beta$ we may always find reasons to distinguish also between $\alpha$ 's proper parts (and parts thereof) and $\beta$ 's. Hence, again, the objection would trade on the unwarranted supposition that co-location is possible at some level of mereological composition but not at other, lower levels.

On the other hand, suppose there are mereological atoms. Then the question arises of why such things can make such a big difference. Not only are atoms sui generis in that they lack any proper parts. They would also be sui generis in that they - and only they-can form more than one composite object at the same time. Why so? Why should lack of mereological structure be a necessary and sufficient condition for something to enjoy such a peculiar ability? What de re intuitions do we have about atoms that justify such a claim? We may have intuitions about houses and cats; but what intuitions do we have about entities all of whose proper parts are mereological atoms? To put it differently, at this point the anti-extensionalist objection would be tantamount to the requirement that EP be amended by adding an unless-clause: 
EP' If $x$ and $y$ are composite objects with the same proper parts, then $x=y-$ unless all proper parts of $x$ and $y$ are atomic.

And such an amendment-I contend-cries for a justification. If one finds the opposition between integral wholes and mere aggregates non-negotiable, why not cash it out explicitly in terms of two different modes of composition? Material simples, as well as composite objects, would combine in one way to yield ordinary mereological sums (the "mere aggregates") and in another way to yield nonmereological composites (the "integral wholes"). Each such mode of composition could be perfectly extensional and the putative anti-extensionalist would at last reveal her true identity: not an anti-extensionalist but a dualist (or a pluralist, if it need be).$^{24}$ Alternatively, for all that has been said one might as well stick to a single mode of composition - parthood-and suppose instead that there are two sorts of atoms, just as there would be two sorts of composites: atoms of one sort would combine to yield so-called integral wholes; atoms of the other sort would combine to yield so-called mere aggregates. Surely these two sorts of atoms could be colocated, if this is true of the composites they yield. So why not say that the limit case we are considering - the only case that could warrant a genuine counterexample to EP-involves co-located entities of different sorts that are made up of colocated atoms of different sorts?

\section{Revenons à Nos Moutons}

No matter how one feels about all these options, the moral I wish to draw is that unless we are given an explanation of why and how one can have co-location of non-identicals at some levels of mereological complexity but not at other levels (and I shall come back to this in the next section), the extensionality of parthood is vindicated. This is not to say that EP implies that co-location be an all-or-nothing affair - that coinciding distinct objects (if such there be) can only have distinct coinciding parts. On the contrary, a glance at Figure 1 will suffice to make the point. We may suppose that $a_{1}$ and $a_{2}$ are co-located even though none of their proper parts is (short of identity). As far as EP goes, co-location of non-identicals may well obtain at the level of larger sums while failing at the level of smaller sums. It is only with respect to certain ways of drawing the line that EP is incompatible,

${ }^{24}$ The same account could in fact be offered to accommodate the opposition wood/object rather than mere aggregate/integral whole. See for instance G. Link, 'The Logical Analysis of Plural and Mass Terms: A Lattice-Theoretical Approach', in R. Bäuerle, C. Schwarze, and A. von Stechow (eds), Meaning, Use, and Interpretation of Language (Berlin: de Gruyter, 1983), pp. 302323. 
namely those ways that correspond to an abrupt change from one level to the "next", as in Figure 4 (where the lower layer may or may not consist of atoms).

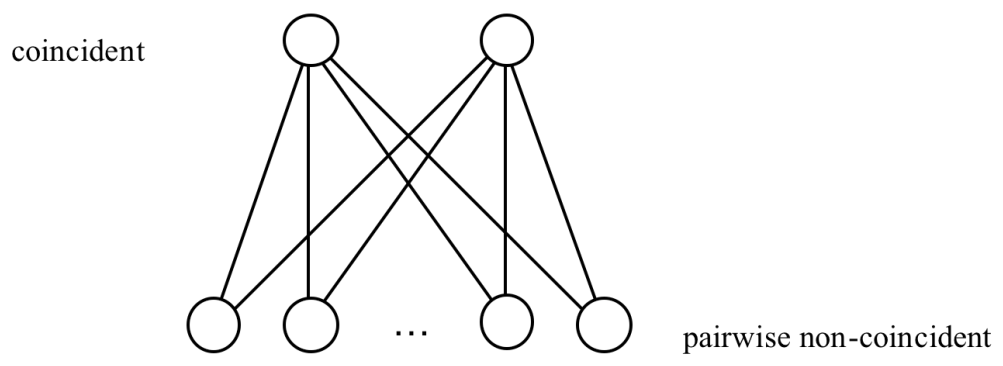

Figure 4

So, now, going back to the issue of the formal-ontological status of mereology, this means that unless the challenge of justifying such abrupt changes is met, EP is available as a formal, domain-independent, metaphysically neutral principle. It is not neutral in the sense that anything goes-that would be of little use. But EP is neutral insofar as the link that it establishes between part-whole structures and identity need not depend on any specific views about the nature of what there is, such as the view that material objects are four- or perhaps five-dimensional entities.

Now enter UC and EC. Clearly, a defense of EP is a necessary condition for any defense of UC, since the latter implies the former. But it is not a sufficient condition. And it is neither necessary nor sufficient to provide a defense of EC, which we have seen to be logically independent of EP. In particular, it is clear that the arguments of the previous sections could not be put forward also on behalf of UC and EC. For those arguments depend crucially on the mereological discernibility of $\alpha$ and $\beta$ (and parts thereof), while the scenario of Figure 1 shows that this is a non-starter when it comes to UC and EC. We could not, for example, argue that insofar as $\alpha_{1}$ (the roof) and $\beta_{1}$ (the underlying wood) are distinct, there are no things of which both $\alpha$ and $\beta$ are sums, let alone things of which both are composed. More would be needed for that purpose.

Nonetheless, it should now be clear why I think that a defense of EP along the lines suggested above can go some way towards a defense of UC and EC as well. In concrete cases, i.e., cases that have attracted the attention of philosophers over the years, the extra bit that would be needed to justify the claims that composition is extensional and unique appears to be unnecessary. Concrete disputes do not concern objects that are mereologically structured as in Figure 1 (or in Figure 2). Nor do they concern objects all of whose proper parts are atoms (if such there be). 
They concern objects such as houses and cats, which have plenty of composite parts and about which it may be reasonable to claim that we have de re intuitions. And they concern such familiar objects insofar as they are claimed to be structured according to the special mereological pattern in Figure 4. This is why, I think, the three principles are often identified by their critics. Thus, to the extent that one of the lessons to be drawn from the defense of EP is that such special patterns cry for a justification, the defense turns automatically into a defense of UC and EC. For it is precisely such patterns that UC and (in special cases) EC intend to rule out.

\section{Taking the Challenge at Face Value}

So everything turns on the above-mentioned challenge: Can any reasons be given to justify the contention that, in some cases, co-location of distinct objects dissolves as we move from one level of mereological composition to the next, lower level?

I have voiced my skepticism, even when the line between the two levels is non-arbitrary (as when it rests on the sui generis mereological behavior of atoms). But of course such a justification need not be given in general, abstract terms. The challenge would be met if one could come up with a good justification in at least some cases. So let us take a look at some more concrete examples where it might be thought that things are indeed so. The house/wood and the house/aggregate scenarios seem to leave the issue undetermined, but other scenarios might be best suited for this purpose, including perhaps scenarios where the entities involved are not material objects but, say, abstract entities. I will consider three new examples, versions of which have occupied a prominent position in recent philosophical discussions. And in each case I will argue that what appear to be good reasons to draw the line founder. Although I realize that this is no conclusive evidence to the effect that a line cannot be drawn in other cases, I hope that this, together with the examples already considered, will at least suffice to illustrate why I take the challenge to be a hard one.

\subsection{First Example}

For a first example, consider Art and Paul, two singers who recently joined to form a duo. ${ }^{25}$ Let

(11) $\mathrm{D}==_{\mathrm{df}}$ the duo Art \& Paul.

(12) $\mathrm{S}==_{\mathrm{df}}$ a mereological sum of Art and Paul.

${ }^{25}$ This example is inspired by the discussion on groups in P. Simons, Parts, ch. 4. 
Here, our artificial and somewhat elusive Tinkertoy pieces are replaced by two people (and the stuff, we may suppose, by their bodies). And we do have good, philosophically sophisticated theories about people that are not grounded exclusively on dubious linguistic intuitions. In particular, we may have good reasons to favor a materialist conception of people, identifying a person with his or her body. Suppose we accept such reasons. And suppose, for the sake of the argument, that we also treat a person's body as the (only) sum of its parts. Then at the level of individual persons we would seem to have good reasons to rule out co-location of non-identicals: there would be just one thing where Art is located, and just one thing where Paul is located. Wouldn't this be compatible with the thought that colocation of non-identicals is nonetheless possible at the next level up? Even a materialist about persons might be strongly inclined to agree, for example, with claims such as the following:

(13) S, but not D, existed several years ago

(14) D, but not S, has such and such legal obligations

(and so on). So even a materialist might be inclined to concede that

(15) $\quad \mathrm{D} \neq \mathrm{S}$.

And wouldn't this be a case of the sort depicted in Figure 4? Wouldn't this show that sometimes we do have good reasons to draw the line so as to meet the challenge?

I don't think it would. For one thing, this is a scenario where a diagnosis along the lines of the second type of response mentioned in Section 2 (different conceptions, different predications) is perfectly plausible. I said that that type of response leads to a deadlock as a general practice, but that does not mean that it is always illegitimate: to the extent that a single example may suffice to meet the challenge, its correctness must be assessed on its own grounds. And in this case the inference to (15) is dubious. We may have good reasons to accept (13), (14), and the like because such statements reflect our intuitions about the appropriate use of the singular terms ' $\mathrm{D}$ ' and ' $\mathrm{S}$ ', given that these terms have different connotations, but this is not to say that such statements must be interpreted as attributing different properties to D and S. On the contrary, we may interpret (13), (14), and the like in such a way as to do justice to the intuition that $\mathrm{D}$ and $\mathrm{S}$ are one and the same entity under two different descriptions - as in

(13') S has been around for several years, but it did not acquire the property of being a duo until recently.

(14') D has such and such legal obligations, but only as long as it enjoys the property of being a duo. 
Surely it takes more to be a duo than to consist of two individuals - the extensionalist may continue - just as it takes more to be a king than to be a person. But that is not to say that a duo is something else than a sum of two individuals, just as a king is not something else than a person. The extra bit that makes the difference is to be explained in terms of the properties that the entities in question come to acquire during their existence. (To put it differently, 'being a duo', like 'being a king', is not a substance-sortal but a phase-sortal.) Likewise, the extensionalist would certainly concede that it would be awkward to assert the sentences that come from (13) and (14) by replacing ' $D$ ' with ' $S$ ', or vice versa. But that is not to say that (15) is true. The substitution would be misleading due to false pragmatic implicatures, and such implicatures disappear as soon as we go for the reading in $(13 ')$ and $(14 ')$.

On the other hand, suppose we reject this line of response. Suppose we insist on the thought that (13), (14), and the like are literally true, hence that 'being a duo' is not just a phase-sortal. Then it seems plausible to say that other statements concerning S and D deserve a similar treatment. For example, someone who is inclined to agree with (13) and (14) should presumably agree also with

(16) Art's left foot is part of S, but it is not part of D.

This is because (16) is but another way of expressing the thought that duos-as also teams, committees, battalions, etc. - have more stringent membership conditions than any old mereological sum: it takes more to be part of a duo than being part of (one of) its members, just as it takes more to be identical with a duo than just consisting of its members. ${ }^{26}$ If so, then we would of course have one more reason for accepting the non-identity in (15). However, it is apparent that this would also dispose of the objection altogether. For if (16) is true, then S and D do not in fact have the same proper parts, hence the truth of (15) would not count as a counterexample to extensionality. Indeed, if statements such as (16) are accepted, it is also apparent that D would not even qualify as a mereological sum of Art and Paul; the relevant mode of composition would not be transitive and it would not, therefore, reflect the mereological use of 'part of'. The putative counterexample would thus founder and the anti-extensionalist objection would turn into a plea for compositional pluralism. (Some authors would object to the transitivity requirement, their reasons stemming precisely from the contemplation of cases such as the one under consideration. Spatial parthood may well be transitive, they say, but

${ }^{26}$ See e.g. F. Moltmann, Parts and Wholes in Semantics (Oxford: Oxford University Press, 1997), ch. 1, and P. Sheehy, 'Sharing Space. The Synchronic Identity of Social Groups', Philosophy of the Social Sciences, 36 (2006), pp. 131-148. 
'part of' need not be interpreted in a purely spatial sense and need not, therefore, be fully closed under transitivity. ${ }^{27}$ I say this reasoning has it the wrong way round. Each different sense of 'part of' picks out a subrelation of parthood simpliciter, and of course a subrelation need not be closed under the same conditions-such as transitivity - as the relation itself. ${ }^{28}$ )

It might be replied that this is too quick. It might be thought that the intuitive truth of (16) trades on the ambiguity between 'part of' understood in its general, mereological sense (first conjunct) and 'part of' understood in a more specific, restricted sense (second conjunct) - that sense that is more perspicuous in the use of such predicates as 'member of' or 'one of'. If so, then (16) would not show that S and $\mathrm{D}$ are mereologically discernible. It would only show that being part of $\mathrm{S}$ is not enough to be part of $\mathrm{D}$ in this special and restricted sense, whose nontransitivity does not affect the transitivity of parthood simpliciter. Fair enough. Here, then, is a third argument on behalf of the extensionalist. Suppose that, unbeknownst to all, Art is Superman. Consider:

(17) Art is part of D, but Superman isn't.

It seems to me that whoever is inclined to accept (13) and (14) should also have no qualms about (17). After all, the contracts are not signed 'Superman' but 'Art', the royalties do not go to Superman's bank account but to Art's, and if the famed superhero in blue leotard showed up at a concert next to Paul it would be big news. So, intuitively, it would seem correct to say that Superman is not part of the duo, although Art is part of it by definition. Yet this cannot be a good reason to conclude that

(18) Art $\neq$ Superman,

for (18) is false by hypothesis. Now, 'part of' is not opaque. So either one gives up the intuition that (17) is true, or else one finds a reasonable way of reading (17) that preserves that intuition in spite of the fact that 'Art' and 'Superman' are, as a matter of contingent fact, co-referential. This may well not be an easy task, but

${ }^{27}$ Besides Rescher (see note 5), see e.g. J. Lyons, Semantics (Cambridge: Cambridge University Press, 1977), vol. I, at p. 313; D. A. Cruse, 'On the Transitivity of the Part-Whole Relation', Journal of Linguistics, 15 (1979), pp. 29-38, and M. A. Iris, B. E. Litowitz, and M. Evens, 'Problems of the Part-Whole Relation', in M. Evens (ed.), Relational Models of the Lexicon: Representing Knowledge in Semantic Networks (Cambridge: Cambridge University Press, 1988), pp. 261288.

${ }^{28}$ Pace I. Johansson, 'On the Transitivity of Parthood Relations', in H. Hochberg and K. Mulligan (eds), Relations and Predicates (Frankfurt: Ontos, 2004), pp. 161-181, at p. 165. For more on this, see my 'A Note on the Transitivity of Parthood', Applied Ontology, 1 (2006), pp. 141-146. 
never mind that. ${ }^{29}$ The point is simply that if these are the options in the case of (17), it is up to the anti-extensionalist to explain why (13) and (14) deserve a different treatment. It is up to the anti-extensionalist to explain why the inference from (17) to (18) is unjustified whereas the inference from (13) and (14) to (15) would be legitimate. Admittedly, this is not a direct argument in favor of the thesis that ' $\mathrm{D}$ ' and ' $\mathrm{S}$ ' are co-referential, let alone a general argument in favor of mereological extensionality. It is, however, another reason for resisting the contention that we have got a good case against it.

\subsection{Second Example}

Consider a different sort of scenario-two words consisting of the same letters. ${ }^{30}$ For instance, let:

$$
\begin{aligned}
& \mathrm{F}==_{\mathrm{df}} \text { the word 'FALLOUT', } \\
& \mathrm{O}={ }_{\mathrm{df}} \text { the word 'OUTFALL'. }
\end{aligned}
$$

Here the Tinkertoy pieces are replaced by linguistic items. And it seems plausible to think that the words are distinct in spite of being composed of the same items (the same letters and, in fact, the same syllables). Do we have a case in point?

Let us distinguish two main options, depending on whether $\mathrm{F}$ and $\mathrm{O}$ are construed as word-types or as word-tokens. In the first case, the non-identity

\section{(21) $\quad \mathrm{F} \neq \mathrm{O}$}

would be indisputable, though it would be significant only insofar as we think of a word-type as constituted by the relevant letter-types (as opposed to the relevant word-tokens, which are obviously distinct). What sort of constitution relation would that be?

If we think a word-type is a set of letter-types, specifically an ordered set, then the relation in question is the ancestral of set membership, and this does not qualify as parthood. For example, it does not satisfy the Weak Supplementation principle, WS, because of the making of singletons. Thus, in that case $\mathrm{F}$ and $\mathrm{O}$ would indeed qualify as distinct entities constructed out of the same (six) constitu-

\footnotetext{
${ }^{29}$ For a diagnosis of the difficulties, see J. M. Saul, 'Substitution and Simple Sentences', Analysis, 57 (1997), pp. 102-108.

${ }^{30}$ This sort of example goes back to N. Rescher, 'Axioms for the Part Relation', at p. 10. One might as well consider sentences consisting of the same words (C. G. Hempel, 'Reflections on Nelson Goodman's The Structure of Appearance', Philosophical Review, 62 (1953), pp. 108-116, at p. 110 ), or tunes made out of the same notes (Rosen and Dorr, 'Composition as a Fiction', at p. 154). Such cases are not significantly different from the one considered here.
} 
ents, but once again they would not qualify as mereological sums of those constituents and the non-identity in (21) would lose its force. (What if we treated ' $x$ is the singleton of $y$ ' as a primitive and reconstructed the rest of set theory in genuine mereological terms $?^{31}$ Specifically, suppose we identified every set with a sum of its singletons, and let

(22) $x$ is a member of $y=_{\mathrm{df}}\{x\}$ is part of $y$.

In that case, provided ordered sets were construed in some standard way, say via the recursive definition

$$
\begin{aligned}
& \langle x, y\rangle=_{\mathrm{df}}\{\{x\},\{x, y\}\} \\
& \left\langle x_{1}, x_{2}, \ldots, x_{n}\right\rangle=_{\mathrm{df}}\left\langle x_{1},\left\langle x_{2}, \ldots, x_{n}\right\rangle\right\rangle \quad(n>2)
\end{aligned}
$$

$\mathrm{F}$ and $\mathrm{O}$ would certainly qualify as mereological sums, but not as sums of their letter-types proper. For example, the parts of $\mathrm{F}$ would comprise, not the letter-type ' $F$ ', but the singleton of its singleton. And since the singleton of the singleton of the letter-type 'F' would not be part of $\mathrm{O}$, the non-identity in (21) would be no threat to extensionality.)

Alternatively, we may think of a word-type as a universal of some sort-a structural universal that is truly composed of its letter-types (and instantiated by its word-tokens). This might still not be enough to yield a counterexample to EP, as two different word-types are bound to involve different string-types ('LOU', for example, would be part of F, not of O), but never mind that. Certainly (21) would now count against both UC and EC. However, it is fair to ask how exactly composition is supposed to work in such cases. For example, what relationship would hold between the letter-type ' $L$ ' and the string-type 'LL'? Clearly the former would have to count as part of the latter, and equally clearly it should be distinguished from the latter, since their tokens are distinct. So this would be a case of proper parthood. But then, again, 'LL' does not have any other parts besides ' $L$ '. A letter-type is supposed to be a universal, and a universal is one, not many: it makes no sense to say that ' $L L$ ' involves ' $L$ ' twice over. ${ }^{32}$ Thus, again, Weak Supplementation would be violated and this is enough to conclude that the apparent counterexample would involve a sui generis constitution relation (if such there be) that is not properly mereological. (To be sure, here I am assuming that letter-types

\footnotetext{
${ }^{31}$ As in Lewis's Parts of Classes.

${ }^{32}$ Lewis takes this to be a reductio of the very idea that there are structural universals; see his 'Against Structural Universals', Australasian Journal of Philosophy, 64 (1986), pp. 24-46, at pp. 34-35. Lewis's point, however, relies on UC and might therefore be deemed circular; see D. M. Armstrong, 'In Defence of Structural Universals', Australasian Journal of Philosophy, 64 (1986), pp. 85-88, at p. 85. Here I am relying exclusively on WS.
} 
are mereologically atomic - arguably a simplification. However, it seems obvious that all linguistic types must be built out of a basic stock of atoms, so at some level WS would have to be violated in this fashion. On the other hand, I do not mean to suggest that taking parthood as the only mode of composition would make the notion of a structural universal unintelligible. It's just that the relevant structure cannot be cashed out directly in terms of parthood. For example, a word-type could be construed as a second-order relational property: $\mathrm{F}$ would be the property of having seven distinct proper parts $x_{1}, \ldots x_{7}$ such that $x_{1}$ is a token of the letter type ' $\mathrm{F}$ ', $x_{2}$ is a token of the letter type ' $\mathrm{O}$ ', $, \ldots, x_{n}$ is a token of the letter type ' $\mathrm{T}$ ', $x_{1}$ is immediately to the left of $x_{2}, x_{2}$ is immediately to the left of $x_{3}, \ldots$, and $x_{6}$ is immediately to the left of $x_{7} \cdot{ }^{33}$ Similarly for O. It is clear, however, that on such an account the non-identity in (21) would not meet the challenge, for there would be no direct mereological relationship between a word-type and its letter-types.)

Perhaps other accounts of the mereology of word-types are possible, but to my knowledge no theory is available at the moment that fits the bill. And unless we have a plausible theory, we can hardly speak of (21) as a genuine counterexample. Let us, then, move on to the second option, where $\mathrm{F}$ and $\mathrm{O}$ are construed as concrete word-tokens. And let us assume for the sake of the argument that $\mathrm{F}$ and $\mathrm{O}$ consist of (i.e., are sums of) the same letter-tokens. On my reckoning, there are only two ways of picturing this twofold assumption.

On the one hand, we may suppose that one of the two word-tokens is obtained from the other by rearranging the relevant letter-tokens. If so, however, then (21) becomes a statement of diachronic non-identity, and it is not obvious that this meets the challenge. A four-dimensionalist would surely deny it: $\mathrm{F}$ and $\mathrm{O}$ would be different inscriptions composed of different parts, different temporal parts of the same seven perduring letter-tokens. But a three-dimensionalist could (and-I think - should) deny it too. For all that has been said, if $\mathrm{F}$ and $\mathrm{O}$ are three-dimensional inscriptions that endure by being wholly present at different times, there is no obvious reason to think that they are not the same thing that is 'FALLOUT'shaped at one time and 'OUTFALL'-shaped at another. Such is the lesson of the problem of temporary intrinsics. ${ }^{34}$ (I can be bent at one time and straight at another.) So I don't think the supposition that one word is obtained from the other by rearranging the relevant letter-tokens meets the challenge.

On the other hand, we may imagine the letter-tokens to be suitably arranged so as to form both words at the same time-for example, they may be arranged in

${ }^{33}$ This follows a suggestion by J. Bigelow and R. Pargetter, 'A Theory of Structural Universals', Australasian Journal of Philosophy, 67 (1989), pp. 1-11.

${ }^{34} \mathrm{I}$ am alluding to the problem raised by Lewis, On the Plurality of Worlds, at pp. $202 \mathrm{ff}$. 
a circle (Figure 5). In this case $\mathrm{F}$ and $\mathrm{O}$ would indeed be co-located, their difference being determined by where in the circle we choose to start. So do we now have a case in point? I say we don't. I say we have got a circular inscription that, curiously, can be read as two different words depending on where we start. But one inscription it is, so (21) is false. Compare: I draw a rabbit that to you looks like a duck (Figure 6). Have I thereby made two drawings? I write ' $p$ ' on my office glass door; from the outside you read ' $q$ '. Have I therefore produced two letter-tokens? And what if Mary joins you and reads it upside down: have I also written the letter ' $b$ '? Surely then I have also written the letter ' $d$ ', as my upside-down office-mate John points out. This multiplication of entities strikes me as ludicrous. There is just one thing there, one inscription, and what it looks (or mean) to you or me or Mary or John is totally irrelevant to what that thing is. Similarly, I say, there is just one inscription in our example, a circular display of letter-tokens, and whether we read it as a 'FALLOUT'-inscription or an 'OUTFALL'-inscription is irrelevant to its mereological structure.

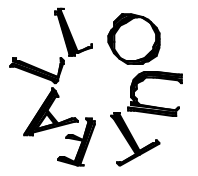

Figure 5

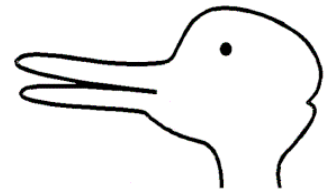

Figure 6

\subsection{Third Example}

Consider a scenario in which I set out to write a letter to my friend Mary and a letter to my friend Luigi, who live together. ${ }^{35}$ Since I only have one sheet of stationary, I first write to Mary (in English) on one side and then to Luigi (in Italian) on the other side. Let

(25) $\quad \mathrm{M}==_{\mathrm{df}}$ my letter to Mary

(26) $\mathrm{L}==_{\mathrm{df}}$ my letter to Luigi.

This is a scenario where we seem to have strong prima facie reasons for claiming that

(27) $\quad \mathrm{M} \neq \mathrm{L}$

35 This example is inspired by K. Fine, 'A Counterexample to Locke's Thesis', The Monist, 83 (2000), pp. 357-361, although Fine's intended target is Locke's thesis (things of the same kind cannot be co-located), not mereological extensionality. 
even though, on the face of it, $\mathrm{M}$ and $\mathrm{L}$ appear to be perfectly co-located. For instance, it seems plausible to say that

(28) $\mathrm{M}$ is written in English, $\mathrm{L}$ in Italian.

(29) $\mathrm{M}$ is written on one side of the paper, $\mathrm{L}$ on the other.

(30) $\mathrm{M}$ was written before $\mathrm{L}$.

(31) Erasing the ink on one side would destroy M (say), not L.

Never mind whether such prima facie reasons are sufficient to warrant the truth of (27). Let us suppose they are. Do we have a case in point? (Obviously I am not talking of the letters understood as abstract entities, otherwise the answer would be trivial. I am talking about the letters understood as concrete particulars: Do they have the same parts?)

It might be observed that the example is not good enough, for one could reasonably maintain that the ink with which the letters are written is bound to make a difference. So let us suppose that-lacking a proper writing tool-I am forced to use a sharp-pointed chopstick to engrave my messages on each side of the paper, which is thick enough. (Let's pretend I do a good job, so that both sides are legible.) Then we just have the engraved paper, no ink. Isn't this a good case of colocated non-identicals that meets the challenge?

One could still dismiss the example by insisting that the letters do not only consist of the paper, but also of my engravings, understood as "negative", immaterial entities. (Surely M and L involve different engravings.) That such immaterial entities are as real as ordinary marks of ink is, after all, a defensible position. ${ }^{36} \mathrm{But}$ it is certainly not a popular position, so this line of response is hardly effective. On the other hand, let us look at the alternatives. Let us suppose the letters consist of nothing but paper. What reasons are there for saying that they have the same proper parts? If $\mathrm{M}$ is written on one side of the paper and $\mathrm{L}$ on the other, isn't their location different? And if their location is different, isn't their mereological composition different too?

I think the answer is obvious if the sheet of paper has some thickness, as we have assumed. For if the paper has thickness, then we could in principle slice it in half in such a way as to separate the two letters (a difficult operation, but not a metaphysical impossibility). So in that case it seems obvious that the two letters are not co-located and do not consist of the same proper parts. Granted, this implies that if the paper weighs 10 grams, then each letter weighs less, and this runs against our inclination to agree with Mary if she said: " $M y$ letter weighs 10

${ }^{36}$ My reasons for thinking so are detailed in R. Casati and A. C. Varzi, Holes and Other Superficialities (Cambridge, MA: MIT Press, 1994). 
grams". ${ }^{37}$ But then, again, would there be anything wrong if she said: "Our letter weighs 10 grams"? Linguistic practices and intuitions are confused here. Similarly, I agree that in ordinary circumstances we are inclined to identify a letter with the whole sheet of paper even if it is just written on one side. But then, again, we might also be inclined to say that in the envisaged scenario I only wrote one letter after all, half of which, in English, was addressed to Mary while the other half, in Italian, was addressed to Luigi. Linguistic practices and intuitions may be interesting in their own right, but they prove too little (or too much) to be given metaphysical credit. That is why they lead to the deadlock mentioned at the beginning.

On the other hand, suppose we ignore the thickness of the paper. Or suppose the paper sheet has zero thickness, in the sense that it only extends in the other two dimensions. Certainly one can still maintain that it is not mereologically atomic, for we may still distinguish between its right and left halves, for instance. And certainly it is still appropriate to speak of the sheet as having two opposite sides, at least in the following sense: there is a way of looking at it on which the engravings (or perhaps I should say: the indentations) are readable in English, and there is another way on which the engravings are in Italian. In this case there is no apparent reason to deny that the letters are truly co-located. But then, again, I don't think we have a counterexample to the extensionalist principles under discussion. For at this point we can still argue according to the pattern illustrated in Sections 3 and 4: If the two letters are co-located, and if they are distinct, then their proper parts are co-located, too-and distinct. Precisely as in the case of the Tinkertoy house, if such claims as (28)-(31) are good enough to distinguish between M and L, similar claims would allow us to distinguish between the right half of M, say, and the corresponding part of L. And this is enough to block the counterexample (at this level as well as at lower levels of decomposition).

\section{Conclusion}

There are, of course, many other interesting scenarios that could be considered to test the challenge, including scenarios where the entities at issue are of a different metaphysical kind than material objects (or word-types). For example, actions and

\footnotetext{
${ }^{37}$ See Fine, 'A Counterexample to Locke's Thesis', at p. 358. Some would actually turn this into a reductio of the non-identity of $\mathrm{M}$ and $\mathrm{L}$, as the total weight should then add up to 20 grams. (See e.g. D. Robinson, 'Can Amoebae Divide Without Multiplying?', at pp. 316-317; D. K. Lewis, On the Plurality of Worlds, at p. 252; D. W. Zimmerman, 'Theories of Masses and Problems of Constitution', at p. 87.) However, this would be a variant of the response appealing to Humean supervenience, so it would be just as controversial; see e.g. L. R. Baker, 'Why Constitution Is Not Identity', Journal of Philosophy, 94 (1997), pp. 599-621, at p. 159.
} 
other events are often cited as entities that might be perfectly co-located and yet distinct, as with the rotation of a metal sphere and its simultaneous getting hot. ${ }^{38}$ But I am inclined to think that no such variant would differ significantly from the cases reviewed here. Sometimes the co-location is illusory. Sometimes it is arguably genuine, casting doubts on the tenability of Locke's thesis ("Things of the same kind cannot be co-located"). But the challenge is not to find a counterexample to that thesis. The challenge is to show that, in some cases, violation of Locke's thesis involves entities whose mereological structure, at some level of composition, is identical. And that challenge is much harder to meet than it might seem-at least it is hard to meet insofar as parthood is understood as a purely mereological relation. ${ }^{39}$

${ }^{38}$ The example is from D. Davidson, 'The Individuation of Events', in N. Rescher (ed.), Essays in Honor of Carl G. Hempel (Dordrecht: Reidel, 1969), pp. 216-234, at p. 231. Events have sometime been distinguished from objects precisely on these grounds; see e.g. A. Quinton, 'Objects and Events', Mind, 88 (1979), pp. 197-214, at p. 201.

${ }^{39}$ The bulk of this paper was prepared for the conference Identity: Ontological Perspectives, held at Vrije Universiteit, Amsterdam (Netherlands), in May 2005. Earlier drafts were presented at colloquia at Tufts University, Syracuse University, and the State University of New York at Buffalo. Later versions were also delivered at the Second Meeting on Analytic Ontology held in Pisa (Italy), July 2005, and at a Workshop on Mereology held in Buenos Aires (Argentina), November 2006, Many thanks to Arianna Betti for her commentary at the conference and to Horacio Banega, Andrea Bottani, Hud Hudson, Mark Heller, Philipp Keller, Kathrin Kolsicki, Kris McDaniel, and Thomas McKay for their helpful criticisms of the earlier and later drafts. This final version benefited also from comments from an anonymous referee of The Philosophical Quarterly. 